\title{
Status, opportunities, and challenges of electrochemical energy storage
}

\author{
Sheng S. Zhang* \\ Electrochemistry Branch, RDRL-SED-C, Sensors and Electron Devices Directorate, U.S. Army Research Laboratory, Adelphi, MD, USA \\ ${ }^{*}$ Correspondence: shengshui.zhang.civ@mail.mil; shengshui@gmail.com \\ Reviewed by: \\ Fernando M. B. Marques, Universidade de Aveiro, Portugal
}

Keywords: electrochemical energy storage, electric vehicle, smart grid, capacitor, lithium-ion battery, lithium-air battery, sulfur battery, redox flow battery

\section{INTRODUCTION}

Today's electricity generation and transportation depend heavily on fossil fuels. As such, electricity generation and transportation have become two major sources of $\mathrm{CO}_{2}$ emissions leading to global warming. The concerns over environmental pollution and finite fossil fuel resources have spurred great interest in generating cleaner electricity from renewable energy sources such as solar, ocean/lake wave, and wind, and in developing electric vehicles (EV). However, the renewable energy sources and energy/power demands by industries and transportation are not constant. For example, sunlight and wind vary from time-totime and from location-to-location, and energy/power demands change from peak time to off-peak time for industries and from accelerating-to-braking for EVs. In order to harvest the renewable energies effectively and for widespread electrification of transportation, electrochemical energy storage (EES) is necessary to smooth the intermittency of renewable electricity generation and reduce or eliminate the $\mathrm{CO}_{2}$ emissions from traditional transportation. The EESs are an indispensable component for future smart grids that integrate significant amounts of renewable energy resources and provide electricity to electrical vehicles. In this article, the status, opportunities, and challenges will be discussed for the future research and development of EESs.

\section{THE TYPE AND STATUS OF EES}

According to the principle of energy storage, EESs are classified as batteries and electrochemical capacitors (also called supercapacitors or ultracapacitors). The batteries are featured with high energy density and stable operating voltage, and are further divided into primary and secondary (or rechargeable) batteries. The electrochemical capacitors are featured with high power capability and linear (sloping) operating voltage, and are further divided into electrochemical double-layer capacitors (EDLCs) and pseudocapacitors. All of these EESs store energy through a faradaic process except for the EDLCs that store energy by physically capturing the opposite charges on the surface of two electrodes.

Primary batteries are devices that convert chemical energy into electricity. They are featured with long shelf life and high energy density, and are generally used in applications that require long service time without need of recharging. Rechargeable batteries store energy in a reversible manner through a reversible redox reaction. Lead-acid batteries with an energy density range of 30-40 Wh/kg are among the oldest rechargeable batteries and still occupy more than $60 \%$ of battery markets. China is the largest market for lead-acid batteries due to the large demand for electric bikes, however, almost $90 \%$ of lead-acid battery manufacturers were closed there in 2011 in response to the significant pollution by $\mathrm{Pb}$ heavy metal in the manufacture and recycling of lead-acid batteries (Bloomberg, 2011). EDLCs are based on a symmetric cell design that consists of two porous carbon electrodes and stores energy at the surface of electrodes in the form of an electric double layer. Since the charges are stored only at the electrode-electrolyte interface without ionic transport in the bulk of electrode materials, the EDLCs have very fast kinetics (power). The EDLCs generally provide less than $10 \mathrm{Wh} / \mathrm{kg}$ energy density in $10^{-2}$ to $10^{2} \mathrm{~s}$ of time scale for thousands of cycles. Pseudocapacitors store energy in both the surface and the bulk of electrode materials, which bridges the EDLCs and rechargeable batteries in terms of energy density and power capability. At the surface, charges are statically stored in the form of an electric double-layer, and in the bulk, ion intercalation takes place accompanied by the transfer of electrons. The pseudocapacitor generally has a $\sim 100$ fold higher capacitance per surface area than an EDLC, and the same electrode materials used in rechargeable batteries can be used in pseudocapacitors such as $\mathrm{V}_{2} \mathrm{O}_{5}$ and $\mathrm{MnO}_{2}$.

\section{OPPORTUNITIES AND CHALLENGES OF EES}

According to the energy levels, the applications of EES can be divided into mobile electronics, transportation, and stationary. Cost and performance are two common challenges for all these EES applications, whereas the requirements for the performances vary with the applications.

\section{MOBILE ELECTRONICS}

Mobile electronics require an energy range of $10-100 \mathrm{Wh}$. In order to be more convenient and appealing, mobile electronics should be smaller and lighter, which places particular requirement for energy density in addition to high power density, long cycle life, and good safety. Commercial Li-ion batteries are available with three classes of cathode materials: lithiated layered transition metal dioxides, lithiated transition metal spinel oxides, and lithium metal phosphates. The state-ofthe-art (SOA) 18650-type Li-ion battery can deliver a $266 \mathrm{Wh} / \mathrm{kg}$ or a $730 \mathrm{Wh} / \mathrm{L}$ of energy density by using a nickel-cobaltaluminum (NCA) cathode (Green Car Congress, 2009). In many cases, two or 
more Li-ion cells are connected in series, parallel, or hybrid of both to meet the energy and power needs of the devices, and the battery module is built into the devices. In addition to the cost, key challenges for the Li-ion batteries used in the mobile electronics are (1) better cathode and anode materials for even higher energy and power densities, (2) abuse tolerance, especially to overcharging and high rate charging, and (3) performance and storage at temperature extremes.

The SOA Li-ion batteries employ graphite as the anode material, whose capacity is limited by its theoretical value $(372 \mathrm{Ah} / \mathrm{kg})$ and relatively low density $\left(2.09-2.23 \mathrm{~g} / \mathrm{cm}^{3}\right)$. On anode, alloy-based anode materials such as silicon, germanium, and tin are promising to replace graphite if their reversibility and cycle life can be improved. On cathode, Li-rich Mnbased materials with a general formula of $\mathrm{xLi}_{2} \mathrm{MnO}_{3}-(1-\mathrm{x}) \mathrm{LiMnO}_{2}$ seem to be the best candidates for high specific capacity, however, two major problems are faced: low Coloumbic efficiency in the first cycle and gradual voltage hysteresis with cycling, which are associated with the irreversible oxidation of oxygen in the lattices and resulting $\mathrm{Li}^{+}$extraction from the Li layers and structural transformation (Mohanty et al., 2013). High voltage (5V) cathode materials such as spinel $\mathrm{Li}_{2} \mathrm{Mn}_{1.5} \mathrm{Ni}_{0.5} \mathrm{O}_{4}$ and olivine $\mathrm{LiCoPO}_{4}$ provide an alternative approach to increasing the energy density of Li-ion batteries. With successes in the development of these materials, the following challenges have emerged mainly because of the high potentials: (1) oxidative and/or catalytic decomposition of the electrolyte solvents on the surfaces of conductive carbon and cathode particles, (2) intercalation of salt anions into the conductive carbon causing structural exfoliation and decrease in electronic conductivity, and (3) oxidation of conductive carbon and anodic corrosion of the cathode current collector.

Overcharging, which often occurs when the customer forgets to disconnect the charger or the charger controller fails to function, not only causes the decomposition of electrolyte solvents but also results in safety hazards. Functional electrolytes capable of tolerating overcharging are highly demanded for advancing the safety of Li-ion batteries. This can be realized by using a redox shuttle additive or a non-flammable solvent. The standard electrolytes used in the SOA Li-ion batteries are composed of $\mathrm{LiPF}_{6}$ and carbonate solvents, in which $\mathrm{LiPF}_{6}$ cannot withstand temperatures above $50^{\circ} \mathrm{C}$ for long periods in the presence of organic solvents and the carbonate solvents get crystallized at low temperatures. The challenge to develop liquid electrolytes with a wide operational temperature range still remains.

Nanotechnology offers many advantages in designing and synthesizing the micro- or nano-structures of the cathode and anode materials, and has successfully improved the power capability of the cathode and anode materials by reducing the particle size and increasing the reaction area. In particular, nanostructure greatly relieves the mechanical stress caused by the large volumetric expansion and contraction during the alloying and dealloying processes, enabling the reversible and durable cycling of many Li-alloy-based anode materials such as $\mathrm{Si}$ and Sn. However, nanostructure meanwhile promotes parasitic reactions within the cell due to increased interfaces between the electrodes and electrolytes, and furthermore the cost and the scale up for mass production remain major obstacles that hinder the applications of nanotechnologies in battery industries. On the other hand, thin film deposition techniques have led to success in microbatteries, which typically offer a capacity density of $\sim 100 \mu \mathrm{A} \mathrm{h} / \mathrm{cm}^{2}$ and find special applications in the field of miniaturized systems, such as autonomous sensors, microelectro-mechanical systems (MEMS), and implantable medical devices. However, the multilayer encapsulation technology must be improved to enable the safe and reliable operation in various types of special environments (Salot et al., 2009).

\section{TRANSPORTATION}

Hybrid electric vehicle (HEV), plug-in hybrid electric vehicle (PHEV), and all-EV provide grand opportunities to reduce the dependency on liquid fuels and $\mathrm{CO}_{2}$ emissions in transportation. Midsized vehicles need a 20-90 kW h energy range, depending on the type of vehicles. The cost and performance are two key challenges for the transportation batteries. The cost includes battery cells, battery management, and packing materials, while the performance is quantified by usable energy density, power density, cycle life, and robustness. In the past decade, commercial success in manganese spinel Li-ion technology has been made by Toyota (Prius HEV), General Motors (Volt PHEV), and Nissan (Leaf EV). The short-term goal of the U.S. Department of Energy (DOE) is to develop a battery system that has a usable energy density of $200 \mathrm{Wh} / \mathrm{kg}$, a charging rate of $3 \mathrm{~h}$, and a cost of $\$ 190$ 300/kW h (Howell, 2012). Such battery systems can typically power a midsized passenger PHEV or EV to drive for $160 \mathrm{~km}$ on a single charge. The long-term goal is for the battery system to have volumetric and gravimetric energy densities of $300 \mathrm{Wh} / \mathrm{L}$ and $250 \mathrm{Wh} / \mathrm{kg}$, respectively, at a cost of $\$ 125 / \mathrm{kW} \mathrm{h}$ for enabling 300-mile range midsized sedans. None of the current Li-ion batteries can meet these goals. Breakthroughs or emerging technologies are needed in the aspects of the materials, manufacture engineering, and pack technology. Although the requirements and challenges for HEVs, PHEVs, and EVs are quite different, the key challenges are summarized as follows:

\section{Cost}

Cost is essential in determining the commercial viability of EVs, and varies with the size and production volume. The current cost for $15 \mathrm{kWh}$ NCA-based OEM batteries ranges from $\$ 650$ to $\$ 790 / \mathrm{kW} \mathrm{h}$, which is far higher than the target of $\$ 250 / \mathrm{kW} \mathrm{h}$ set by the USABC (United States Advanced Battery Consortium) (Dinger et al., 2010). A more recent study shows that the battery costs came down from $\$ 1,300 / \mathrm{kW} \mathrm{h}$ in 2007 to $\$ 500 / \mathrm{kWh}$ in 2012 , still far away from the targets of $\$ 300 / \mathrm{kWh}$ in 2015 and $\$ 125 / \mathrm{kWh}$ by 2022 set by the DOE (Khan and Kushler, 2013). Without major breakthroughs in battery materials and technologies, the USABC and DOE's targets are unlikely to be achieved in the near future. On the cell level, Na-ion and $\mathrm{Mg}$-ion are good candidates for the lowcost battery chemistries. However, $\mathrm{Na}$ has a larger ionic radius and higher redox potential than $\mathrm{Li}$, meaning that the $\mathrm{Na}^{+}$ion is much more difficult to move in the cathode materials (low power) and the Na-ion cell offers lower working voltage (low energy). On the other hand, $\mathrm{Mg}^{2+}$ ion has much larger charge/radius ratio, its diffusion in 
the cathode host is slow (low power) due to the strong electrostatic interaction between the divalent $\mathrm{Mg}^{2+}$ ion and the host anionic frame.

\section{Energy density and power density}

Requirements for the energy and power densities of the battery systems are quite different for each type of EV. For HEV applications, the batteries are operated in the middle state-of-charge (SOC) range, and high power is eminently required for fast charging and discharging in kinetic braking and accelerating of the vehicles. For PHEV and EV applications, both the energy and power densities are required for long drive range, necessary speed, and short charging time. Adjusting the thickness of electrodes and the content of active materials is a common practice to meet the energy and power requirements for specific applications. A general rule is that the high thickness of the electrodes and the high content of the active materials favor the energy density, whereas the opposite is true for the power density. For the same battery chemistry, therefore, there is a tradeoff between the energy density and power density. Today's battery cells can reach energy densities of $140-170 \mathrm{Wh} / \mathrm{kg}$, and the battery packs are typically $30-40 \%$ lower in consideration of the weight of the packing materials and battery management (Dinger et al., 2010).

In addition to the approaches described in the mobile electronics section, the battery systems beyond Li-ion, such as conversion cathode batteries, Li-air batteries, and Li-S batteries, are under intensive investigation because of their high theoretical energy density. The conversion cathodes are based on a conversion reaction between Li metal and transition metal oxides, halides, or sulfides (Cabana et al., 2010). These cathode materials store energy through a replacement reaction of transition metal by $\mathrm{Li}$, and are able to provide much higher specific capacity through the multielectronic redox reaction. The power density would be a challenge for these materials because of the slow redox kinetics in relation to the low electrical conductivity of the conversion materials and the nature of the two-solid-phase reaction (i.e., the $\mathrm{MX}_{n}$ phase and $\mathrm{M}$ phase for $\mathrm{MX}_{\mathrm{n}}$ materials). Other challenges are the dissolution of $\mathrm{MX}_{\mathrm{n}}$ materials in the liquid electrolytes and the growth of the $\mathrm{MX}_{\mathrm{n}}$ particle size upon repeated cycling. The dissolution will results in the $\mathrm{M}^{\mathrm{n}+}$ ions migrating to and reducing (depositing) on the anode.

Non-aqueous electrolyte Li-air batteries attract great attention because they potentially provide threefold to fourfold energy densities of the Li-ion batteries with a theoretical energy density of $11,248 \mathrm{Wh} / \mathrm{kg}$ Li. Before this technology can come into use, many breakthroughs must be made, including (1) non-aqueous electrolyte being stable against $\mathrm{Li}_{2} \mathrm{O}_{2}, \mathrm{LiO}_{2}$, and oxygen anionic radicals intermediate, (2) electrocatalyst capable of selectively catalyzing reversible two-electron redox of oxygen and effectively reducing the significant voltage hysteresis in charging, (3) oxygen selective membrane that effectively prevents the $\mathrm{CO}_{2}$, moisture, and electrolyte solvents from crossover while allowing oxygen to diffuse, (4) means to increase $\mathrm{Li}$ cycling efficiency and prevent the growth of lithium dendrites, and (5) means to protect carbon and cathode current collector from anodic oxidization/corrosion. Meanwhile, safety concern with the coexistence of lithium peroxide and organic electrolyte in the discharged state must be seriously taken into account. In addition, the carbon air electrode, the discharge products, and the need of membranes, auxiliary mechanics, and packaging materials would significantly reduce the overall energy density.

Li-S batteries are of particular attraction due to their high theoretical energy density $(2600 \mathrm{Wh} / \mathrm{kg}$ or $1256 \mathrm{Wh} / \mathrm{L}$ based on sulfur) as well as low cost and natural abundance of elemental sulfur. Key challenges of the Li-S batteries are the low energy (Coulombic) efficiency, fast capacity fading, and high self-discharge rate, all of which are related to the dissolution of long-chain lithium polysulfide (PS, $\mathrm{Li}_{2} \mathrm{~S}_{\mathrm{n}}$, $n \geq 4$ ) into liquid electrolytes and resulting parasitic reactions with the $\mathrm{Li}$ anode. In fact, dissolution in liquid electrolytes is the intrinsic nature of long-chain PS and is essential for enabling the reactions of isolating sulfur and PS in Li/S batteries. Thus, the real challenge for Li/S batteries is how to reduce or eliminate the parasitic reactions of the dissolved PS with the $\mathrm{Li}$ anode. For the solution, two approaches have been intensively investigated: (1) confining the dissolved PS within the cathode prior to reduction into insoluble $\mathrm{Li}_{2} \mathrm{~S}_{2}$ or $\mathrm{Li}_{2} \mathrm{~S}$, and (2) protecting the $\mathrm{Li}$ anode from reactions with the dissolved PS. Sulfur-carbon composites based on various nanotechnologies are effective in absorbing or adsorbing PS within the cathode, however, the employment of a large mass ratio of carbon significantly reduces the overall energy density and the extra synthesis process greatly adds to the cost of the sulfur materials. The protection of $\mathrm{Li}$ anode necessitates $\mathrm{a} \mathrm{Li}^{+}$-ionic conductive solid-state electrolyte. The chemical and physical compatibilities of this solid electrolyte with the Li metal and PS solution are two major challenges for many solidstate electrolytes. $\mathrm{xP}_{2} \mathrm{~S}_{5}-(1-\mathrm{x}) \mathrm{Li}_{2} \mathrm{~S}$ family glasses are one of the most stable solid-state electrolytes against the Li metal, however, they dissolve into the organic liquid electrolytes and/or react with sulfur and PS to form soluble polysulfide complexes. An alternative improvement is to promote the sulfur reaction into a solid phase by using a sulfurized carbon cathode material or a solid-state electrolyte. The former in which the short S-S chains are covalently bound onto carbon surface is challenged by a decrease in the specific capacity as a result of the introduction of significant amounts of carbon backbones (Zhang, 2013). The latter is challenged by the chemical reactions of the solid-state electrolyte with elemental sulfur and PS, which change the chemistry of the cathode-electrolyte interface and accordingly reduce the ionic conductivity of the interface between the electrolyte and cathode.

\section{Service temperature range}

Batteries for transportation require capability of all-weather operations. The present Li-ion batteries perform poorly at both temperature extremes, due to the low ionic conductivity at low temperatures caused by the phase transitions such as solvent crystallization and salt precipitation, and the electrolyte degradation at high temperatures caused by the parasitic reactions among the solvents, salt $\left(\mathrm{LiPF}_{6}\right)$, and the electrode materials. For operation of large-capacity batteries at low temperature, discharging could benefit from the self-heating due to Joule heat produced during the discharge, however, the charging is greatly challenged by the Li plating 
on the graphite anode. When operating in summer, the internal temperature of the battery pack can easily reach over $80^{\circ} \mathrm{C}$ as a combined result of the hot ambient and Joule heat. There is no doubt that developing an electrolyte that enables the operations of $\mathrm{Li}$-ion batteries over a wide temperature range is a key challenge for transportation applications.

\section{Safety}

Accidents happen when chemical energy in the battery is released in forms of heat, fire, or explosion in a short timeframe, the destructivity of which is proportional to the chemical energy stored in the battery. Overcharging adds extra energy into the battery in the forms of chemical energy and Joule heat, and hence is considered to be the most dangerous abuse. There is a contradiction between the energy density and safety, for instance, safer batteries such as those using $\mathrm{Li}_{2} \mathrm{Mn}_{2} \mathrm{O}_{4}$ and $\mathrm{LiFePO}_{4}$ cathodes have low energy densities, prohibitive in energy density for long drive distance. In order to enable long drive distance, one must develop the highly energetic cathode and anode materials with a focus on guaranteeing safety. Nearly all battery-related accidents reported are attributed to the internal circuit-shorting, caused either by thermal runaway or by material failures, especially the mechanical failure of separators, such as dimensional shrinkage near the melting temperature and penetration of the small conductive particles like $\mathrm{Li}$ dendrites, conductive carbon, graphite, or even metallic impurities introduced during the manufacturing. Therefore, a key challenge for the performance and safety of the transportation batteries is to develop a separator that not only has high porosity and low thickness to allow fast ion transport but also can tolerate abuse conditions such as high temperature and mechanical penetration. A low cost and facile method for improved safety is the direct coating of a porous ceramic layer onto the surface of cathode, anode, or both (Zhang, 2012). In this case, the ceramic layer can still isolate the cathode and anode from contact with each other even when the polyolefin separator is molten. Other challenges include the development of safer cathode and anode materials, non-flammable electrolytes, and advanced battery management systems (BMS). Non-flammable electrolytes are of utmost importance in the case of accidents where thermal runaway may be unavoidable. The SOA batteries use highly flammable electrolytes, and a battery fire can be easily initiated by thermal runaway, as reported for a few EV accidents.

\section{Calendar life and cycle life}

Transportation applications require at least 15 years of calendar life and over thousands of cycle numbers before the capacity degrades to $80 \%$ of original capacity. Under laboratory test conditions, today's batteries have met the EV's cycle life requirement, however, their calendar life is still a hurdle. Without exception, the performance deterioration of $\mathrm{Li}$-ion batteries are due to the structural degradation of electrode materials and the impedance growth of the battery cell, which are closely associated with the chemical reactions of the electrolyte solvents and electrode materials, especially at the fully charged state. The degradation reactions of solvents consume $\mathrm{Li}^{+}$ions from the limited amount of cathode materials, which imbalance the capacity ratio of the cathode and anode, result in the structural degradation of the cathode materials, and significantly increase the impedance of the battery.

\section{Battery management system}

For transportation applications, hundreds or even thousands of battery cells are integrated, through the connections of series, parallel, and the hybrid of both, into a pack. The BMS is a crucial element that dynamically monitors and controls the thermal and electrical status of each individual battery cell. The BMS, typically consisting of a thermal management and an electrical management, enables the battery pack to operate safely and reliably and extends the service life of the battery pack (Lu et al., 2013). The thermal management guarantees each individual cell operating within the safe temperature range, and the electrical management enables each individual cell to run in a healthy and safe manner. A recent estimate shows that the battery pack and management occupy approximately $65 \%$ of the total cost for $15 \mathrm{~kW} \mathrm{~h} \mathrm{NCA} \mathrm{bat-}$ tery packs in an average cost range from $\$ 650$ to $\$ 790 / \mathrm{kWh}$ (Dinger et al., 2010). Increasing the management efficiency and lowering the cost, volume, and weight of the management units are two important challenges to make the Li-ion technologies more competitive in the transportation market.

Beside the above key criteria, other challenges include theoretical modeling and simulations for new materials, battery cell, and battery modules, as well as low-cost process technologies for material synthesis, battery cell manufacture, and integration of battery modules.

\section{STATIONARY (GRID)}

Stationary applications require energy range from a few kilowatt hour for home solar energy systems to many megawatt hour for load-leveling grids. The former can be met by lead-acid batteries, and the latter by batteries of a variety of chemistries from NiMH batteries through redox flow batteries to sodiumsulfur batteries (NASs). Since the batteries are installed in the base, the requirement for the energy density is not as critical as those in the mobile electronic and transportation applications. Key requirements for the stationary applications are cost (including both the unit and maintenance), energy efficiency, service life (cycle number and life span), and power capability. All vanadium redox batteries (VRBs) and NASs are in particular cost competitive and have been used in the grids for balancing the day-night electricity fluctuations and load-leveling the electricity generated from intermittent renewable energy sources.

The VRBs, conceived by NASA researchers in 1979, are being widely used for balancing peak power and loadleveling power generated by renewable energy sources throughout the world. Typically, the VRBs use two porous carbon electrodes as the positive and negative current collectors, respectively, and sulfuric acid as the electrolyte. Vanadium active species are respectively dissolved into sulfuric acid as the anolyte $\left(\mathrm{V}^{3+} / \mathrm{V}^{2+}\right)$ and catholyte $\left(\mathrm{VO}_{2}{ }^{+} / \mathrm{VO}^{2+}\right)$, and stored in two separate reservoirs. In the battery system, the anolyte and catholyte chambers are separated by a proton-exchange membrane and the redox reactions of vanadium species take place on the surface of two carbon electrodes. Typically, the VRBs have a working voltage range of $1.15-1.55 \mathrm{~V}$ with an energy density range of $15-25 \mathrm{Wh} / \mathrm{kg}$ of electrolyte, depending on the concentration of electrolyte. 
Determined by the nature of the materials and battery system, the VRBs have the following weaknesses: (1) narrow operational temperature range $\left(10-40^{\circ} \mathrm{C}\right)$ due to the crystallization or precipitation of sulfuric acid and vanadium salts at low temperature and water evaporation at high temperature, (2) low energy efficiency (65-75\%) due to the crossover of vanadium species from one to the other electrolyte chamber, and the consumption of extra energy by external mechanical pumps, (3) asymmetric flow of water and vanadium species by the osmotic pressure and electromigration effect in the charging and discharging processes, which change the concentration of electrolytes and imbalance the capacity ratio of the anolyte and catholyte, and (4) low energy density limited by the solubility of vanadium salts. While cost reduction is the most notable challenge, other technical challenges are to develop: (1) a membrane that has good mechanical and chemical (against strong acid) stabilities, high proton conductivity, and cationic selectivity to minimize the crossover of vanadium cations, (2) a carbon electrode that has high hydrophilicity, high electronic conductivity, high surface area, suitable porosity, and high electrocatalytic activity to the redox of vanadium species, and (3) stack modeling, design, and technology for improving system performance and reducing cost.

The NASs were initially developed by Ford Motor Company in late 1960s for EV applications and commercialized in the 1980s by NGK Insulators Inc. for stationary applications. To date, NGK has installed more than 250 stations with power capacity larger than $500 \mathrm{~kW}$ throughout the world, with the largest one being a $34 \mathrm{MW} / 245 \mathrm{MW}$ h system built in northern Japan for stabilizing a $51 \mathrm{MW}$ wind farm. The NASs use a $\beta$-alumina ceramic as the $\mathrm{Na}^{+}$-ionic conductive solid-state electrolyte, and are designed in a tubular shape with a wall thickness of about $1-2 \mathrm{~mm}$ to maintain structural and mechanical stability. In order to retain the high $\mathrm{Na}^{+}$-ionic conductivity necessary for the cell reaction, the batteries are operated at 300$350^{\circ} \mathrm{C}$, at which both $\mathrm{Na}$ and $\mathrm{S}$ are in the molten state, with an operational voltage range of 1.78-2.21 $\mathrm{V}$, depending on the SOCs. Featured with high energy density (theoretically, $\sim 760 \mathrm{Wh} / \mathrm{kg}$ ), high energy efficiency, and low maintenance requirements, NASs have been recognized as the most economically feasible EES option for the stationary energy management and have occupied nearly $65 \%$ of the market share of large scale energy storage batteries (Dufo-Lopez et al., 2009). Despite the great successes mentioned above, cost reduction and performance improvements are still two challenges. The $\beta$-alumina ceramic tube is the key element for determining battery cost and operation. Other essential materials for safety and performance are the sealing materials and current collectors. Technically, the mechanical and chemical stabilities of these materials against the molten $\mathrm{Na}$ and $\mathrm{S}$ should be further improved. The interfaces between $\beta$-alumina tube and active materials and between active materials and current collectors are essential for determining the polarization (a factor to determine the power and energy efficiency), reliability, and durability. These interfaces are affected by many factors such as chemical reaction/corrosion, wetting, surface coating, and electrode porosity. Fundamental understanding and better materials are needed for optimizing the interfaces and increasing the reliability and durability. In addition, the innovative designs for battery cell and stack, manufacturing technologies, and monitoring/controlling systems must be identified so as to promote the widespread deployment of grid storages.

\section{CONCLUDING REMARKS}

Electrical energy storage is a crucial component for the reduction of both $\mathrm{CO}_{2}$ emissions and the dependency on fossil fuels. This can be achieved by balancing the electricity demands and load-leveling electricity outputs for the effective harvest of renewable energy resources. The EES technologies are relatively mature for the mobile electronics market, however, grand challenges are faced for the transportation and stationary applications. The cost determines the acceptance by the market, and the safety determines the suitability of the technologies as well as the confidence of the consumers. With these two top priorities, future research and development should focus on the operation performance and reliability, including energy and power densities, energy efficiency, operational temperature range, cycle number, and life span. Rechargeable batteries are important enablers for an effective implementation of renewable energy resources and a wide expansion of vehicle electrification. However, none of the present battery technologies can meet the requirements of these applications. A hybrid of rechargeable batteries and supercapacitors may be an option to allow higher and faster energy storage at the lower cost and longer lifetime necessary for major market enlargement. Further implementation and advancement of EES technologies require the collaboration of interdisciplinary scientists and engineers in areas from fundamental understanding and modeling, material synthesis, and characterization to system design and engineering with the support of local governments in policy and finance. Finally, advanced recycling technology should be pursued to save finite resources and protect our environment from the mass manufacture and applications of energy storage devices.

\section{ACKNOWLEDGMENTS}

The author expresses his deep appreciation to Drs K. Xu, J. Read, and C. Lundgren for their critical reading of the manuscript and valuable suggestions.

\section{REFERENCES}

Bloomberg. (2011). China Shuts 90\% of LeadAcid Battery Makers in State Crackdown. http://www.bloomberg.com/news/2011-11-15/ china-shuts-90-of-lead-acid-battery-makersassociation-says.html

Cabana, J., Monconduit, L., Larcher, D., and Palacin, M. R. (2010). Beyond intercalation-based Li-ion batteries: the state of the art and challenges of electrode materials reacting through conversion reactions. Adv. Mater. 22, E170-E192. doi:10.1002/ adma.201000717

Dinger, A., Martin, R., Mosquet, X., Rabl, M., Rizoulis, D., Russo, M., et al. (2010). Batteries for Electric Cars-Challenges, Opportunities, and the Outlook to 2020. Boston, MA: The Boston Consulting Group.

Dufo-Lopez, R., Bernal-Agustin, J. L., and DominguezNavarro, J. A. (2009). Generation management using batteries in wind farms: economical and technical analysis for Spain. Energy Policy 37, 126-139. doi:10.1016/j.enpol.2008.08.012

Green Car Congress. (2009). Panasonic Develops New Higher-Capacity 18650 Li-Ion Cells: Application of Silicon-Based Alloy in Anode. Osaka: Japan. http://www.greencarcongress.com/ 2009/12/panasonic-20091225.html [accessed Oct. 23, 2013]. 
Howell, D. (2012). EV Everywhere Grand Challenge: Battery Status and Cost Reduction Prospects. http://www1.eere.energy.gov/vehiclesandfuels/ pdfs/ev_everywhere/5_howell_b.pdf [accessed October 23, 2013]

Khan, S., and Kushler, M. (2013). Plug-in electric vehicles: Challenges and opportunities. Report No. T133. American Council for an Energy-Efficient Economy.

Lu, L., Han, X., Li, J., Hua, J., and Ouyang, M. (2013). A review on the key issues for lithium-ion battery management in electric vehicles. J. Power Sources 226, 272-288. doi:10.1016/j.jpowsour.2012.10.060

Mohanty, D., Kalnaus, S., Meisner, R. A., Rhodes, K. J., Li, J., Payzant, E. A., et al. (2013). Structural transformation of a lithium-rich
$\mathrm{Li}_{1.2} \mathrm{Co}_{0.1} \mathrm{Mn}_{0.55} \mathrm{Ni}_{0.15} \mathrm{O}_{2}$ cathode during high voltage cycling resolved by in situ X-ray diffraction. J. Power Sources 229, 239-248. doi:10.1016/j. jpowsour.2012.11.144

Salot, R., Martin, S., Oukassi, S., Bedjaoui, M., and Ubrig, J. (2009). Microbattery technology overview and associated multilayer encapsulation process. Appl. Surf. Sci.256S, S54-S57. doi:10.1016/j.apsusc. 2009.09.086

Zhang, S. S. (2012). "Effective approach toward safe Li-ion battery," in Battery Safety Conference, Las Vegas, NV.

Zhang, S. S. (2013). Sulfurized carbon: a class of cathode materials for high performance lithium/sulfur batteries. Front. Energy Res. 1:10. doi:10.3389/fenrg. 2013.00010
Received: 30 October 2013; accepted: 22 November 2013; published online: 05 December 2013.

Citation: Zhang SS (2013) Status, opportunities, and challenges of electrochemical energy storage. Front. Energy Res. 1:8. doi: 10.3389/fenrg.2013.00008

This article was submitted to Energy Storage, a section of the journal Frontiers in Energy Research.

Copyright (c) 2013 Zhang. This is an open-access article distributed under the terms of the Creative Commons Attribution License (CC BY). The use, distribution or reproduction in other forums is permitted, provided the original author(s) or licensor are credited and that the original publication in this journal is cited, in accordance with accepted academic practice. No use, distribution or reproduction is permitted which does not comply with these terms. 